\title{
A Method for Electroless Nickel Plating on Aluminum Alloy Surface
}

\author{
Ming Chen ${ }^{1}$, Wei Dong ${ }^{2}$, Cherry Qin ${ }^{3}$ \\ ${ }^{1}$ Dongfeng Commercial Vehicle Technology Center, Wuhan, China \\ ${ }^{2}$ Faculty of General Education, Wuhan International Trade University, Wuhan, China \\ ${ }^{3}$ SGS-CSTC Standards Technical Services Co., Ltd. Wuhan Branch, Wuhan, China
}

Email address:

xf_chenming@163.com (Ming Chen)

\section{To cite this article:}

Ming Chen, Wei Dong, Cherry Qin. A Method for Electroless Nickel Plating on Aluminum Alloy Surface. Engineering Science. Vol. 5, No. 3, 2020, pp. 33-37. doi: 10.11648/j.es.20200503.12

Received: January 17, 2020; Accepted: June 8, 2020; Published: July 23, 2020

\begin{abstract}
According to the following plating processes: deoiling $\rightarrow$ washing $\rightarrow$ pickling $\rightarrow$ washing $\rightarrow$ drying $\rightarrow$ weighing $\rightarrow$ electroless plating $\rightarrow$ washing $\rightarrow$ drying $\rightarrow$ weighing. It can obtain Ni-P deposit on aluminum alloy. It studied the influence of bath composition and process parameters on the composition and deposition rate of the alloy coating. Under temperature of $85 \sim 90^{\circ} \mathrm{C}$, nickel sulfate hexahydrate $15 \sim 35 \mathrm{~g} / \mathrm{L}$, sodium hypophosphite $10 \sim 30 \mathrm{~g} / \mathrm{L}$, sodium citrate $5 \sim 10 \mathrm{~g} / \mathrm{L}$, tartaric acid $1 \sim 2 \mathrm{~g} / \mathrm{L}$, $\mathrm{pH} 3 \sim 5$, reaction time 30 60min, load factor $1.0 \sim 2.0 \mathrm{dm}^{2} / \mathrm{L}$. The microstructure, surface morphology, composition and valence of the elements in the alloy coating were studied by metallographic microscope, SEM, EDS and other modern analytical methods. The size of spherical grain was below 1 um and compact distribution. The chemical coatings were mainly composed two elements, which were phosphorous and nickel. The mass percentage of phosphorous was about $15 \%$, and the other one was about $80 \sim 85 \%$. The corrosion resistance of the alloy coating was studied by CASS [1] test method, through 80h CASS test detection, the protection class of chemical coating can be reached 5. The relevant evaluation criteria can be referred to GB/T 6461-2002 [2]. The results show that the Ni-P binary amorphous alloy can be successfully prepared by this process.
\end{abstract}

Keywords: Electroless Plating, Alloy, Plating, Ni, P, Amorphous Alloy

\section{Introduction}

Amorphous alloy [3, 4] is applied to ultra-rapid cold solidification, during which the atoms cannot be arranged in an orderly manner to crystallize. The solid alloy obtained is a long-range disordered structure, and there is no grain or grain boundary of crystalline alloy. In 1911, G. T. Bly et al. theorized that amorphous alloys could be made from melt quench. Amorphous alloys are a new type of metal materials developed in the 1970s. In 1946, Brenner and Riddel [5, 6] obtained the first electroless Ni-P amorphous coating in a solution consisting of nickel salts and sodium hypophosphite salts, and it was widely used in the PCB [7], cast iron [8], glass microspheres [9, 10], carbon [11], titanium [12], $\mathrm{SiC}$ ceramic [13], magnesium alloys [14-16], PVC [17].

There are many researches on electroless nickel plating on aluminum matrix in China [18-20], but the content of phosphorous element is not high, and the anti-corrosion ability is also poor.

This paper mainly studies electroless nickel plating on aluminum alloy surface to improve its hardness and corrosion resistance, expand its application range and strengthen its service capability.

\section{Experimental Conditions and Methods}

Materials and composition: 6061 aluminum alloy (magnesium0.8-1.2\%, ferrum0.7\%, silicon0.4-0.8\%, copper $0.15-0.4 \%, \quad$ zinc $0.25 \%$, chromium $0.04-0.35 \%$, manganese $0.15 \%$, titanium $0.15 \%$ ).

Experimental condition: Structure analysis of electroless Ni-P alloy coating with 6061aluminum alloy plate of $15 \mathrm{~cm} \times 7 \mathrm{~cm} \times 0.1 \mathrm{~cm}$ as substrate.

Plating process: deoiling $\left(20 \mathrm{~g} / \mathrm{L} \mathrm{NaOH}, 20 \mathrm{~g} / \mathrm{L} \mathrm{Na}_{2} \mathrm{CO}_{3}\right.$, ultrasonic stirring $5 \mathrm{~min}$, room temperature) $\rightarrow$ washing (DI water, room temperature $) \rightarrow$ pickling $\left(20 \% \mathrm{H}_{2} \mathrm{SO}_{4}\right.$, ultrasonic stirring $5 \mathrm{~min}$ ) $\rightarrow$ washing (DI water, room temperature) $\rightarrow$ drying (blow 
dry, room temperature) $\rightarrow$ weighing $\rightarrow$ electroless plating $\left(\mathrm{Ni}_{2} \mathrm{SO}_{4} \cdot 6 \mathrm{H}_{2} \mathrm{O} \quad 15 \sim 35 \mathrm{~g} / \mathrm{L}, \mathrm{Na}_{2} \mathrm{HPO}_{2} \quad 10 \sim 30 \mathrm{~g} / \mathrm{L}\right.$, complexing agent $\mathrm{A}$ and $\mathrm{B}, \quad 85 \sim 90^{\circ} \mathrm{C}, \mathrm{pH} 3 \sim 5,40 \mathrm{~min}$, load factor $1.0 \sim 2.0 \mathrm{dm}^{2} / \mathrm{L}$ ) $\rightarrow$ washing (DI water, room temperature) $\rightarrow$ drying (blow dry, room temperature) $\rightarrow$ weighing.

Composition of deoiling solution: $20 \mathrm{~g} / \mathrm{L}$ sodium hydroxide and $20 \mathrm{~g} / \mathrm{L}$ sodium carbonate solution; Composition of acid lotion: sulfuric acid solution with $20 \%$ mass content. Bath formula: nickel sulfate hexahydrate $15 \sim 35 \mathrm{~g} / \mathrm{L}$, sodium hypophosphite $10 \sim 30 \mathrm{~g} / \mathrm{L}$, complexing agent A: sodium citrate
$0 \sim 10 \mathrm{~g} / \mathrm{L}$, complexing agent $\mathrm{B}$ : tartaric acid $0 \sim 2 \mathrm{~g} / \mathrm{L}$, complexing agent $\mathrm{C}$ : EDTA $0 \sim 2 \mathrm{~g} / \mathrm{L}$, complexing agent $\mathrm{D}$ :

Reactive condition: $85 \sim 90^{\circ} \mathrm{C}, \mathrm{pH}: 3 \sim 5$, load factor: $1.0 \sim 2.0 \mathrm{dm}^{2} / \mathrm{L}$.

Research method: the quality ratio, nickel salt content, sodium hypophosphite content and polishing performance indexes of different complexing agents at different time were investigated. The surface grain morphology and element content of the coating were detected by $\mathrm{Su}-70$ scanning electron microscope and energy spectrum.

\section{Results and Discussions}

\subsection{Effect of Coating Time on Coating Quality}

Table 1. The coating time and coating quality.

\begin{tabular}{llllll}
\hline Coating time (min) & $\mathbf{6}$ & $\mathbf{1 8}$ & $\mathbf{3 3}$ & $\mathbf{4 0}$ \\
\hline Weight quality $\Delta \mathrm{m}(\mathrm{mg})$ & 10 & 70 & 90 & 90 \\
Film deposition rate $\left(\mathrm{mg} / \mathrm{h} \cdot \mathrm{cm}^{2}\right)^{*}$ & 0.65 & 1.52 & 1.06 & 0.88 \\
The mass fraction of the Ni element (\%) & 23.09 & 67.33 & 81.02 & 1.10 \\
The mass fraction of the P element (\%) & 6.52 & 13.56 & 15.76 & 82.11 \\
The mass fraction of the Al element (\%) & 69.17 & 18.59 & 2.66 & 15.83 \\
\hline
\end{tabular}

*Note: The effective area of the deposit was $11 \mathrm{~cm} \times 7 \mathrm{~cm} \times 2=154 \mathrm{~cm}^{2}$, the same as below.

The coating time has a great influence on the deposition of the coating. Table 1 studies the deposition rate of the coating at different times of $6 \sim 60 \mathrm{~min}$ and the contents of $\mathrm{Ni}$ and $\mathrm{P}$ elements in the coating: it found that when the content is less than $33 \mathrm{~min}$, the content of $\mathrm{Ni}$ element in the coating is less than $81 \%$ and the content of $\mathrm{P}$ element is less than $15 \%$. The reaction time was extended to $60 \mathrm{~min}$, and the $\mathrm{Ni}$ content in the coating was $84 \%$, which was $3.8 \%$ higher than that in $33 \mathrm{~min}$. The content of P element was $15.33 \%$, which was $2.7 \%$ less than that at $33 \mathrm{~min}$. If the reaction time is too long, it will lead to the consumption and decomposition of the plating solution, while if the reaction time is too short, Ni-P deposition cannot be formed. The reaction time of $40 \mathrm{~min}$ is appropriate, which can ensure that the $\mathrm{P}$ content in the coating is at a high value of $15.83 \%$ and the Ni content is above $82 \%$. After $40 \mathrm{~min}$, the surface of aluminum alloy are completely covered by $\mathrm{Ni}$ atoms and $\mathrm{P}$ atoms, so the content of $\mathrm{Al}$ element will not be detected.

\subsection{Effect of Complexing Agent on Coating}

Table 2. The mass ratio of complexing agent and coating quality.

\begin{tabular}{|c|c|c|c|c|}
\hline \multirow{2}{*}{$\begin{array}{l}\text { The mass ratio of } \\
\text { complexing agent A: B }\end{array}$} & A: $5 \mathrm{~g} / \mathrm{L} \mathrm{B:} 1 \mathrm{~g} / \mathrm{L}$ & A: $5 \mathrm{~g} / \mathrm{L} \mathrm{B}: 2 \mathrm{~g} / \mathrm{L}$ & A: $7 \mathrm{~g} / \mathrm{L} \mathrm{B}: 2 \mathrm{~g} / \mathrm{L}$ & A: $10 \mathrm{~g} / \mathrm{L} \mathrm{B}: 2 \mathrm{~g} / \mathrm{L}$ \\
\hline & $5: 1$ & $5: 2$ & $7: 2$ & $10: 2$ \\
\hline Weight quality $\Delta \mathrm{m}(\mathrm{mg})$ & 160 & 120 & 110 & 110 \\
\hline Film deposition rate $\left(\mathrm{mg} / \mathrm{h} \cdot \mathrm{cm}^{2}\right)$ & 1.56 & 1.17 & 1.07 & 1.07 \\
\hline
\end{tabular}

Note: The nickel salt $15 \mathrm{~g} / \mathrm{L}$, sodium hypophosphite $10 \mathrm{~g} / \mathrm{L}$, the reaction time is $40 \mathrm{~min}$, and temperature is $85-90^{\circ} \mathrm{C}$.

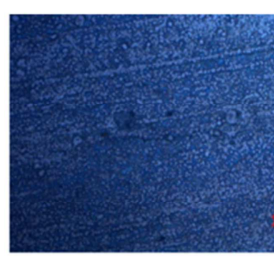

(a)

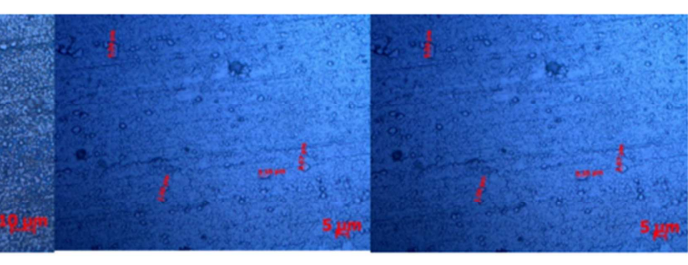

(b)

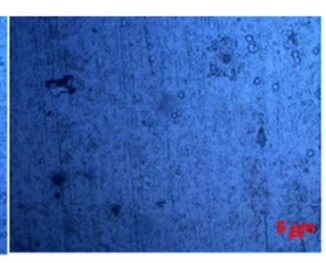

(d)

Figure 1. Ni-P coating morphology under different proportions of complexing agent $A$ and B (1000 times).

(a) Complexing agent $\mathrm{A}$ and $\mathrm{B}=5: 1$; (b) complexing agent $\mathrm{A}$ and $\mathrm{B}=5: 2$;

(c) Complexing agent $\mathrm{A}$ and $\mathrm{B}=7: 2$; (d) complexing $\mathrm{A}$ and $\mathrm{B}=10: 2$.

As can be seen from table 2 and figure 1, the ratio of complexing agent is adjusted when the main salt and reducing agent are unchanged and the mass ratio is $15: 10$. When the mass ratio of sodium citrate and tartaric acid is 5: 1 , the coating is more uniform, dense and the deposition rate is the maximum, so it can get the best condition while the ratio of complexing A and complexing B is 5: 1 . 


$$
\begin{gathered}
3 \mathrm{H}_{2} \mathrm{PO}_{2}^{-}+2 \mathrm{H}^{+} \rightarrow \mathrm{H}_{2} \mathrm{PO}_{3}^{-}+2 \mathrm{P}+3 \mathrm{H}_{2} \mathrm{O} \\
\mathrm{Ni}^{2+}+2 \mathrm{H}_{2} \mathrm{PO}_{2}^{-}+2 \mathrm{H}_{2} \mathrm{O} \rightarrow \mathrm{Ni}+2 \mathrm{HPO}_{3}^{2-}+4 \mathrm{H}^{+}+\mathrm{H}_{2} \uparrow \\
\mathrm{M}+\mathrm{n} \mathrm{H}{ }^{+} \rightarrow \mathrm{M}^{\mathrm{n}+}+\mathrm{n} / 2 \mathrm{H}_{2} \uparrow
\end{gathered}
$$

From formula (2), it can be seen that the concentration of $\mathrm{H}^{+}$ increases, which increases the concentration of products, and the equilibrium moves in the direction of the reverse reaction, inhibiting the deposition of $\mathrm{Ni}$ atoms. When the concentration of complexing agent $\mathrm{B}$ tartaric acid increased, the concentration of $\mathrm{H}^{+}$in the solution increased and the deposition rate of $\mathrm{Ni}$ decreased.

\begin{tabular}{|c|c|c|c|c|}
\hline \multirow[t]{2}{*}{ The mass ratio of Ni salt: $P$ salt } & $\begin{array}{l}\text { Ni salt: } 20 \mathrm{~g} / \mathrm{L} \text { P salt: } \\
10 \mathrm{~g} / \mathrm{L}\end{array}$ & $\begin{array}{l}\text { Ni salt: } 25 \mathrm{~g} / \mathrm{L} \text { P salt: } \\
10 \mathrm{~g} / \mathrm{L}\end{array}$ & $\begin{array}{l}\text { Ni salt: } 30 \mathrm{~g} / \mathrm{L} \text { P salt: } \\
10 \mathrm{~g} / \mathrm{L}\end{array}$ & $\begin{array}{l}\text { Ni salt: } 35 \mathrm{~g} / \mathrm{L} \text { P salt: } \\
10 \mathrm{~g} / \mathrm{L}\end{array}$ \\
\hline & 20: 10 & 25: 10 & 30: 10 & 35: 10 \\
\hline The mass ratio of complexing agent $\mathrm{A}$ : $\mathrm{B}$ & $5: 1$ & $5: 1$ & $5: 1$ & $5: 1$ \\
\hline Weight quality $\Delta \mathrm{m}(\mathrm{mg})$ & 130 & 120 & 150 & 110 \\
\hline Film deposition rate $\left(\mathrm{mg} / \mathrm{h} \cdot \mathrm{cm}^{2}\right)$ & 1.27 & 1.17 & 1.46 & 1.07 \\
\hline
\end{tabular}

\subsection{Effect of Nickel Salt Content on Coating}

Table 3. The content of nickel salt and coating quality.

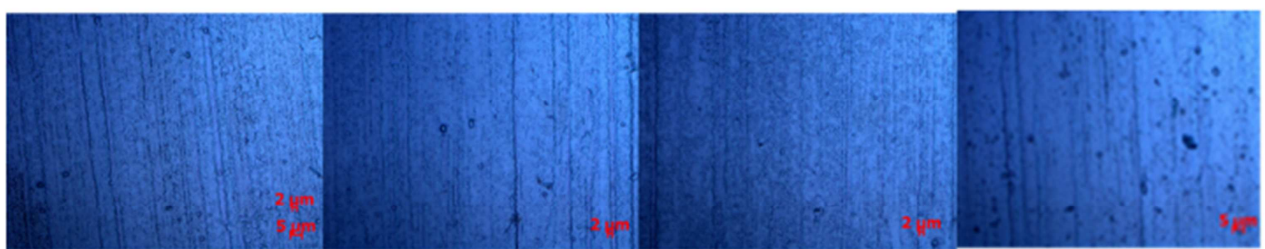

(a)

(b)

(c)

(d)

Figure 2. The morphology of Ni-P coating under different proportions of nickel and phosphorus salt (1000 times).

(a) The mass ratio of Ni salt: $\mathrm{P}$ salt=20: 10; (b) The mass ratio of Ni salt: $\mathrm{P}$ salt=25: 10;

(c) The mass ratio of Ni salt: P salt=30: 10; (d) The mass ratio of Ni salt: P salt=35: 10 .

The content of nickel salt has a great influence on the deposition rate of the coating, as can be seen from table 3: when the mass ratio of nickel phosphorus salt is $30: 10$, the deposition rate of the coating reaches the maximum, reaching $1.46 \mathrm{mg} / \mathrm{h} \cdot \mathrm{cm}^{2}$. However, when the mass ratio of $\mathrm{Ni} / \mathrm{P}$ is 15 : 10 , the deposition rate of the coating is the smallest, only 1.07 $\mathrm{mg} / \mathrm{h} \cdot \mathrm{cm}^{2}$. A doubling of the nickel salt content increases the deposition rate of the coating by $36 \%$, which is consistent with the principle of equilibrium movement: increase the concentration of the reactants, shift the equilibrium toward the products, and increase the reaction rate. As the concentration of the reactant $\mathrm{Ni}^{2+}$ increases, the reaction rate accelerates, which is conducive to the precipitation of $\mathrm{Ni}$. When the content of nickel salt increases by 1 times, the concentration of nickel salt continues to increase, the deposition rate of the coating decreases instead, possibly because the plate surface has a certain thickness of Ni-P coating, at this time, because of the exclusion of $\mathrm{Ni}^{2+}$ by the atomic layer in the coating, the deposition rate of the coating decreases. As can be seen from figure 2, with the increase of nickel ion content, the coating becomes more uniform and denser. From above all, it can include that the best mass ratio of nickel salt and hypophosphite salt is 30: 10 .

\subsection{The Corrosion Resistance Testing}

From Figure 4, the corrosion resistance of aluminum alloy surface coatings was tested by the $80 \mathrm{hCASS}$ test method, and the samples were rated after the corrosion test $[19,20]$. The final electroless plating process conditions are as follows: hexahydrate nickel sulfate $30 \mathrm{~g} / \mathrm{L}$, sodium hypophosphite $10 \mathrm{~g} / \mathrm{L}$, sodium citrate $5 \mathrm{~g} / \mathrm{L}$, tartaric acid $1 \mathrm{~g} / \mathrm{L}$, reaction time $40 \mathrm{~min}$, heating temperature $85 \sim 90^{\circ} \mathrm{C}$., load factor $1.0 \sim 2.0 \mathrm{dm}^{2} / \mathrm{L}$. The deposition rate could be up to $1.56 \mathrm{mg} / \mathrm{h} \cdot \mathrm{cm}^{2}$, the film owned the best quality. The coating had the best corrosion resistance and the protection level can reach 5 .
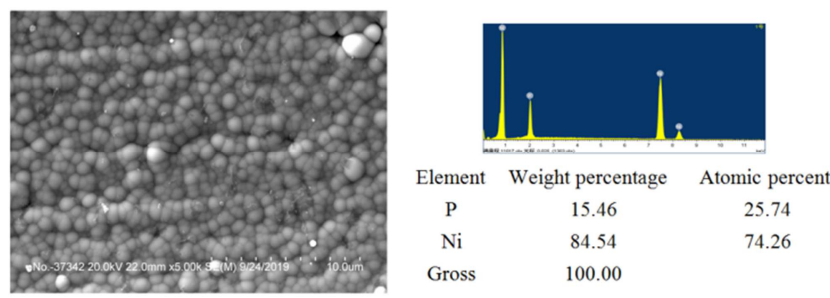

Figure 3. The microstructure and energy spectrum of Ni-P coating under SEM (5000 times).

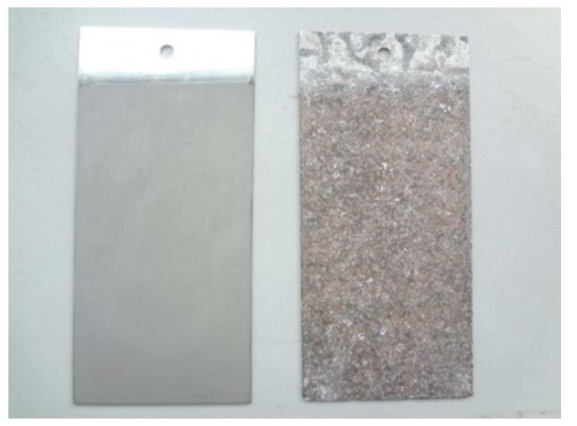

Figure 4. The appearance of Ni-P coating before and after 80hCASS test. 
After 146h NSS test, the surface of $6061 \mathrm{Al}$ alloy appeared many tiny hole erosion, but $6061 \mathrm{Al}$ alloy plate with Ni-P electroless plating had no from Figure 5. It shown that Ni-P electroless plating improved the resistance of corrosion of matrix. According to GB 6461, the protection of level can reach 5 .

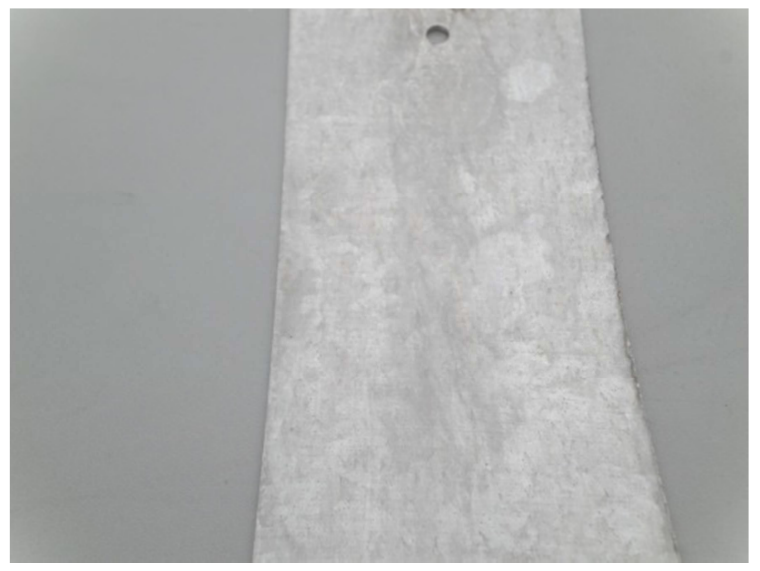

(a)

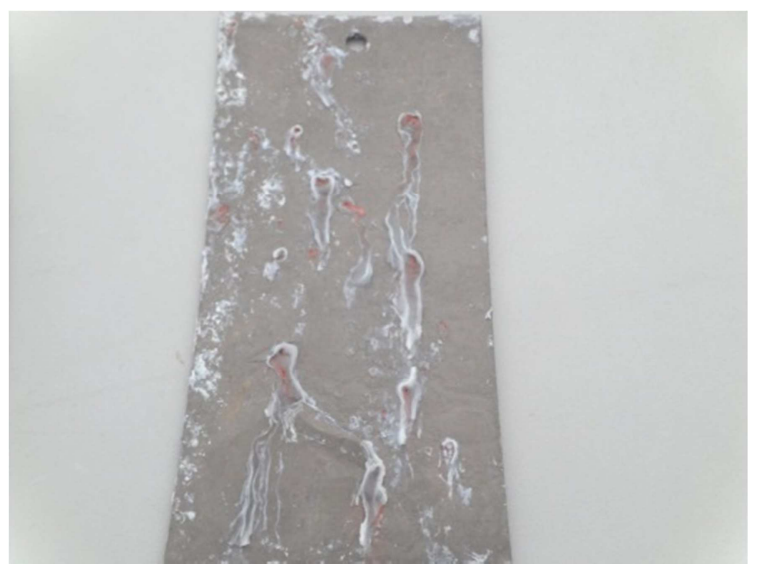

(b)

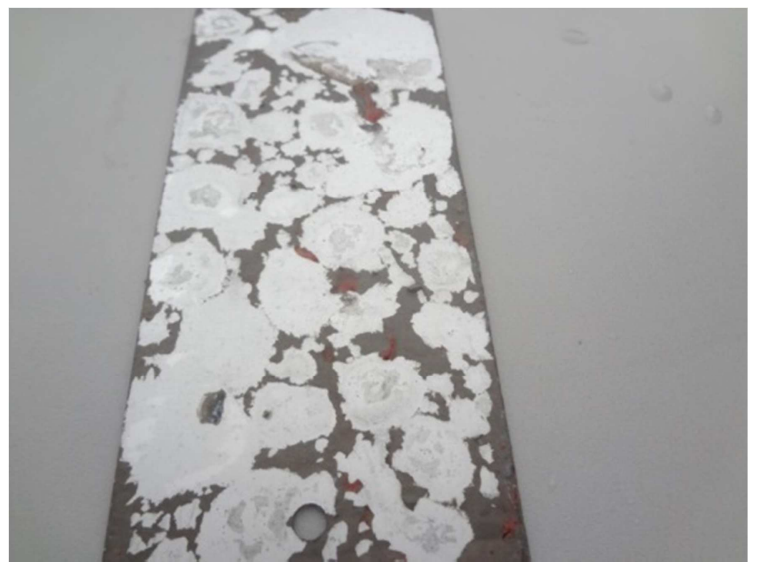

(c)

Figure 5. 146h NSS test.

(a) $6061 \mathrm{Al}$; (b) Ni-P electroless plating film; (c) peel off the Ni-P electroless plating film.

\subsection{The Roughness of Ni-P Electroless Plating}

Table 4. The roughness of Ni-P electroless plating.

\begin{tabular}{lll}
\hline The sample category & 6061Al alloy & Ni-P electroless plating \\
\hline Roughness (um) & $0.1-0.15$ & $0.4-0.9$ \\
\hline
\end{tabular}

Before electroless plating, the roughness value of $6061 \mathrm{Al}$ alloy was only $0.1-0.15 \mathrm{um}$, after electroless plating, the roughness value of Ni-P electroless plating could be up to 0.4-0.9um. Because the accumulation of atoms on the surface of aluminum alloy, which increased the thicker of coating. But the growth of membrane is irregular, which is subject to some external conditions. Temperature, time, ions concentration, mixing way, the placement state of sample in the bath and so on. It is impossible to achieve the absolute consistency of the surface film, so there are differences in roughness, but most are less than lum. Generally, the roughness value is about $0.5 \mathrm{um}$, which is five times of aluminum alloy.

\subsection{The Hardness of Electroless Plating}

Table 5. The hardness of electroless plating.

\begin{tabular}{lll}
\hline The sample category & matrix & Ni-P electroless plating \\
\hline Hardness (HV) & $100-110$ & $120-140$ \\
\hline
\end{tabular}

From table 5. The hardness value of matrix was 100-110HV under pressure of a kilogram of force. After plating, the hardness value of Ni-P electroless plating was $120-140 \mathrm{HV}$ under same load. Comparing before and after plating data, the hardness value was increased by $20 \%$ to $30 \%$. So it can be inclued that according to Ni-P electroless plating method, the hardness of $6061 \mathrm{Al}$ will be improved. According to GB/T 4340.1-2009 Metallic materials--Vickers hardness test--Part 1: Test method.

\subsection{The Thickness of Plating}

The aluminum alloy plate covering Ni-P coating was cut into a square of $1 \mathrm{~cm} * 1 \mathrm{~cm}$ by the method of wire cutting. Then the surface of test sample was cleaned by ultrasonic in $75 \%$ ethanol solution for $5 \mathrm{~min}$, drying at room temperature.

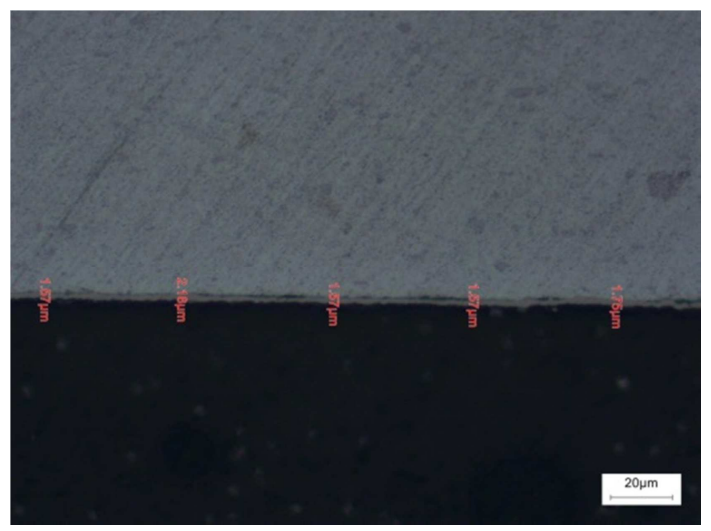

Figure 6. The thickness of plating.

From Figure 6, the thickness of plating was test by 
metallographic microscope. The reference standard for detection method was GB/T 6462-2005 Metallic and oxide coatings--measurement of coating inckness--microscopical method. The value of thickness was 1.5 to $2.2 \mathrm{um}$.

\section{Summary}

1. The composition of bath (main salt, reducing agent and complexing agent) and process parameters (time and temperature) have great influence on the composition and deposition rate of the coating, which concentration of nickel sulfate hexahydrate is $30 \mathrm{~g} / \mathrm{L}$, reducing agent is $10 \mathrm{~g} / \mathrm{L}$, complexing agent sodium hypophosphite is $5 \mathrm{~g} / \mathrm{L}$, complexing agent sodium citrate is $1 \mathrm{~g} / \mathrm{L}$, reaction time is $40 \mathrm{~min}$, reaction temperature is $85 \sim 90^{\circ} \mathrm{C}$, load factor is $1.0 \sim 2.0 \mathrm{dm}^{2} / \mathrm{L}$.

2. The surface micromorphology of Ni-P alloy coating is spherical protuberance with particle size less than 1 um. With the increase of $\mathrm{Ni}$ content, the coating becomes more uniform and denser.

3. After polishing, the surface roughness is improved, the surface area in contact with the plating solution increases, but the deposition rate was decreased.

4. According to the corrosion resistance test of $80 \mathrm{~h}$ CASS and $146 \mathrm{~h}$ NSS, both of the Ni-P electroless plating on the surface of 6061 aluminum alloy could be up to protection level 5 . The test data show that it has good corrosion resistance.

\section{References}

[1] GB/T 12967.3-2008 Test methods for anodic oxidation coatings of aluminium and aluminium alloys-Part 3: Copper accelerated acetic acid salt spray test (CASS test).

[2] GB/T 6461-2002 Methods for corrosion testing of metallic and other inorganic coatings on metallic substrates-Rating of test specimens and manufactured articles subjected to corrosion tests.

[3] L. C. Zhang, J. Xu. Glass-forming ability of melt-spun multicomponent ( $\mathrm{Ti}, \mathrm{Zr}, \mathrm{Hf})-(\mathrm{Cu}, \mathrm{Ni}, \mathrm{Co})-\mathrm{Al}$ alloys with equiatomic substitution. Journal of Non-Crystalline Solids 347 (2004), 166-172.

[4] L. C. Zhang, Z. Q. Shen, J. Xu. Mechanically milling-induced amorphization in Sn-containing Ti-based multicomponent alloy systems. Materials Science and Engineering A 394 (2005), 204-209.

[5] A. Brenner, G. E. Riddell, J. Res. Natl. Bureau Standards 37 (1) (1946).

[6] A. Brenner, G. E. Riddel. Nickel plating by chemical reduction. U. S. Patent 2532283a. Dec. 1950.
[7] Jian-hui Lin, Chong Wang, Shouxu Wang. Initiation electroless nickel plating by atomic hydrogen PCB final finishing [J]. Chemical Engineering Journal, 2016, 306 (15): 117-123.

[8] II-Cho Park, Seong-Jong Kim. Effect of lead nitrate concentration on electroless nickel plating characteristics of gray cast iron [J]. Surface and Coatings Technology, 2019, 376 (25): 2-7.

[9] Shao-Feng Zhou, Qiao-Xin Zhang, Hao Liu. Microwave absorption performance of magnetic Fe-Ni-P nanoparticles electrolessly plated on hollow glass microspheres [J]. Materials Chemistry and Physics, 2012, 134 (1): 224-228.

[10] Guo-Xun Zeng, Jian-Kun Yang, Ren-Peng Hong. Preparation and thermal reflectivity of nickel antimony titanium yellow rutile coate hollow glass microspheres composite pigment [J]. Ceramics International, 2018, 44 (8): 8788-8794.

[11] So-Young Cheon, So-Yeon Park, Young-Mok Rhym. The effect of bath condition on the electroless nickel plating on the porous carbon substrate [J]. Current Applied Physics, 2011, 11 (3): 790-793.

[12] Ce Gao, Lei Dai, Wei Meng. Electrochemically promote electroless nickel-phosphorous plating on titanium substrate [J]. Applied Surface Science, 2017, 392 (15): 912-919.

[13] Lai-Ma Luo, Ze-Long Lu, Xiao-Yue Tan, Xiao-Yu Ding, Li-Mei Huang, Ji-Gui Cheng, Liu Zhu, Yu-Cheng Wu. A specific chemical activation pretreatment for electroless nickel plating on $\mathrm{SiC}$ ceramic powders [J]. Powder Technology, 2013, $249,431-435$.

[14] Bo-Nian Hu, Rui-Xue Sun, Gang Yu, Ling-Song Liu. Effect of bath $\mathrm{pH}$ and stabilizer on electroless nickel plating of magnesium alloys $[\mathrm{J}]$. Surface and Coatings Technology, 2013, $228,84-91$.

[15] Zhong-Cai Shao, Zhi-Qiang Cai, Rong Hu, Shou-Qiang Wei. The study of electroless nickel plating directly on magnesium alloy [J]. Surface and Coatings Technology, 2014, 249, 42-47.

[16] Ayushi Thakur, Swaroop Gharde, Balasubramanian Kandasubramanian. Electroless nickel fabrication on surface modified magnesium substrates [J]. Defence Technology, 2019, 15 (4): 636-644.

[17] Ming-Qiu Wang, Jun Yan, Shi-Guo Du, Hao Qin. A novel process of electroless nickel plating on PVC with semi-IPN hydrogel pretreatment [J]. Journal of Alloys and Compounds, 2013, 557, 270-273.

[18] Yong-Jun Zhang. High speed Ni-P electroless plating on 6063 aluminum alloy extruded profiles [J]. Materials Protection, 2018, 06, 54-58.

[19] Peng-Ju Zhang. Study on electroless Ni-W-P alloy plating technology of 6061 aluminum alloy for automobile [J]. Electroplating and Environmental Protection, 2019, 04, 46-48.

[20] Gang Liu. Study on electroless nickel plating on aluminum lithium alloy and corrosion resistance of film [J]. Electroplating and Finishing, 2018, 04, 12-17. 